\title{
Diurnal Activity of the San Salvador Curly-tailed Lizard (Leiocephalus loxogrammus parnelli)
}

\author{
Kyle J. Dlugolecki, Dustin R. Deisher, Myles D. Karle, and Nicholas P. Kemp \\ Department of Biology, Avila University, Kansas City, Missouri 64145
}

$\mathrm{T}_{s}$ The San Salvador Curly-tailed Lizard (Leiocephalus loxogrammus parnelli; Fig. 1) is endemic to San Salvador Island, Commonwealth of the Bahamas. These lizards generally frequent edges of large open areas, particularly rocky sites, but also sandy beaches, more densely vegetated coastal habitats, and human settlements, but are less abundant in scrub and shrub habitats (Schwartz and Henderson 1991). They frequently are encountered around some of the ruins dating to the Loyalist Era after the American Revolution (Hillbrand et al. 2011). These lizards are omnivorous opportunistic foragers that will sit and wait to ambush prey but also actively search for food (Schoener et al. 1982). Males reach a snoutvent length (SVL) of $90 \mathrm{~mm}$ and females $70 \mathrm{~mm}$ (Schwartz and Henderson 1991).

Little is known about the natural history of Leiocephalus l. parnelli, but Henderson and Powell (2009) summarized information on activity in other West Indian species of Leiocephalus. Many species for which data exist exhibit bimodal activity patterns by avoiding the hottest times of day. Individuals of some other species are active throughout the day, although lizards might retreat to cover when the sky is overcast, delay appearance in the morning due to wind or clouds, or restrict activity until after the heat of the day has passed.

During a three-day period in May 2013, we conducted hourly surveys to determine when and in which microhabitats San Salvador Curly-tailed Lizards were active throughout the day.

\section{Methods}

We established a 230-m transect (Fig. 2) through the ruins of "Watling's Castle" (Fig. 3) and conducted hourly surveys on three consecutive days (17-19 May 2013) beginning at 0730 $\mathrm{h}$ and ending at $1730 \mathrm{~h}$. We recorded ambient temperature 1 $\mathrm{m}$ above the ground while sheltered from wind and sun at the beginning of each survey with a quick-reading electronic thermometer with a type K thermocouple (Fluke Corp., Everett,

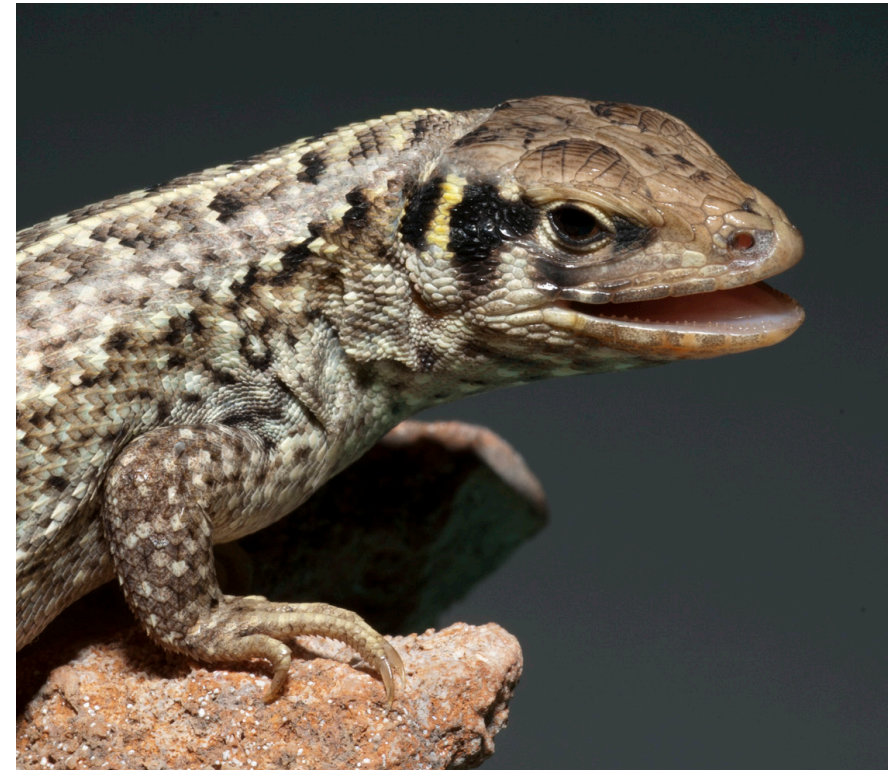

Fig. 1. An adult female San Salvador Curly-tailed Lizard (Leiocephalus loxogrammus parnelli) from scrub habitat near Rocky Point. Photograph by Robert Powell.

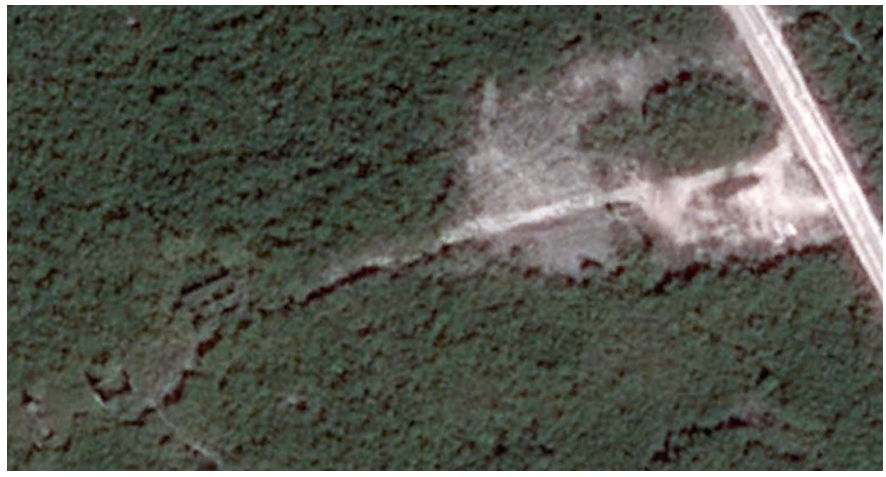

Fig. 2. A Google Earth( image of "Watling's Castle." The 230-m transect extended from the road $\left(23^{\circ} 57^{\prime} 16.49^{\prime \prime} \mathrm{N}, 74^{\circ} 32^{\prime} 46.53^{\prime \prime} \mathrm{W}\right)$ along a path through the parking area, up a hill (the wide gray area in the image), and along a ridge past the principal ruins (Fig. 3) to an area where little remained beyond partial walls and piles of rock (extreme lower left of the image). Included in the transect were several narrow trails (one of which is visible in the image) branching off the main trail. 


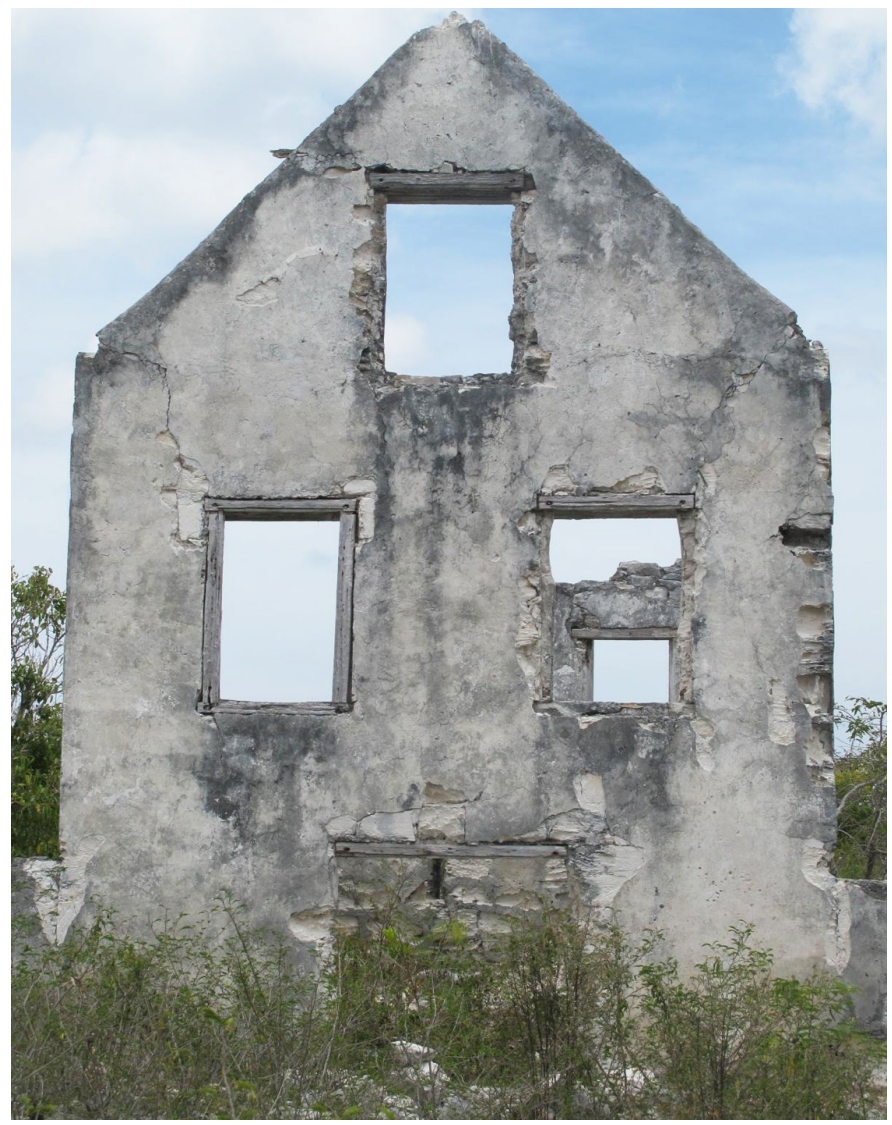

Fig. 3. In 1680, a pirate named John Watling supposedly chose San Salvador as his retreat. Ruins known as Watling's Castle provided views of both eastern and western sides of the southern end of the island. As romantic as these tales are, local historian, Kathy Gerace, clearly demonstrated that the ruins are actually a late 18th-century Loyalist plantation house. Photograph by Tiffany Schultheis.

Washington, USA). We identified individuals as adult males, small adults of undetermined sex, or juveniles, none of which were neonates. We recorded microhabitat (rock/vegetation) and insolation (sun/shade). Also, based on observations of congeners climbing into vegetation (e.g., Burns et al. 1992; Fig. 4), we noted whether the lizard was on an elevated perch (yes/no). We made observations in only one direction while walking along the transect to avoid re-counting the same individuals during any one survey (some individuals, however, were undoubtedly counted multiple times during the entire study).

We used StatView ${ }^{\circledR} 5.0$ (SAS Institute Inc., Cary, North Carolina) for statistical tests; Chi-square tests to compare the frequencies of lizards on rocks or associated with vegetation, in sun or shade, and on elevated perches or not, ANOVA to compare temperatures at which lizards in the three size classes were encountered, and t-tests to compare ambient temperatures when lizards were in sun or shade or on elevated perches or not. All means are presented \pm one SD. For all tests, $\alpha=0.05$.

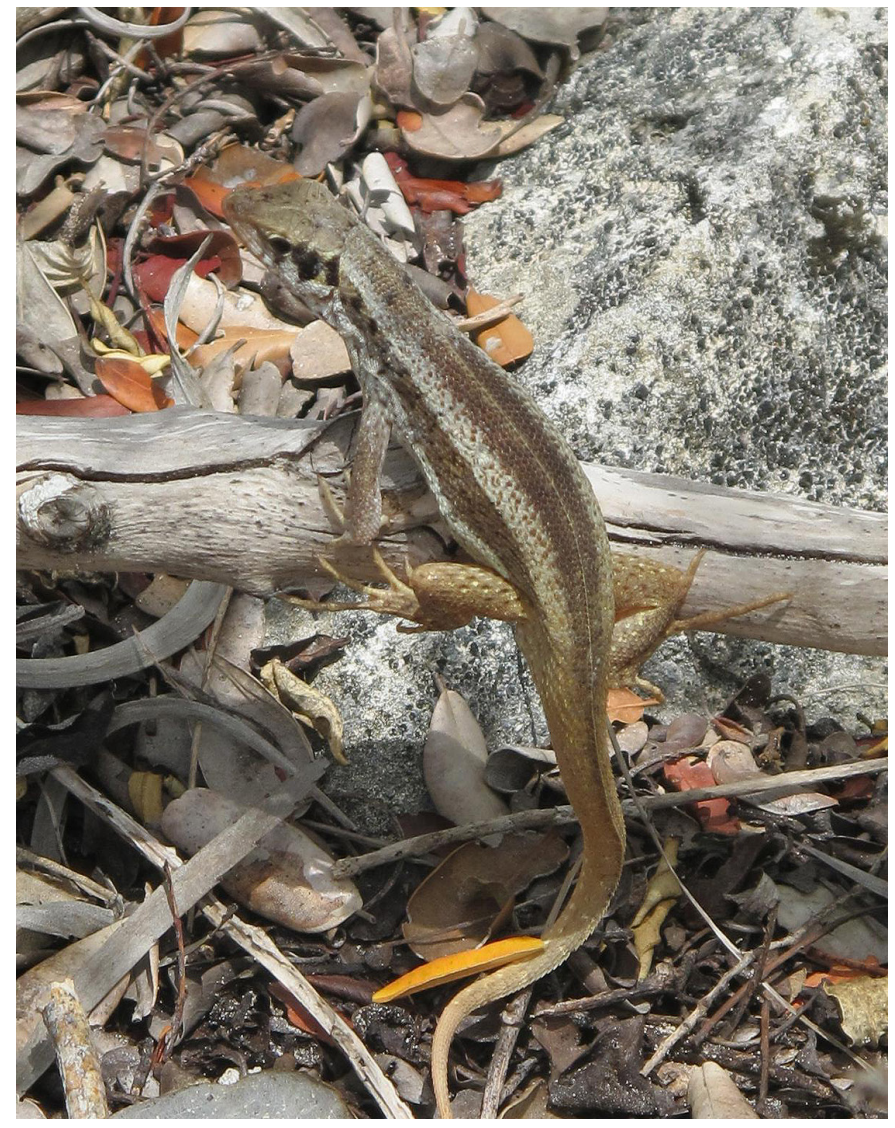

Fig. 4. Lizards in the genus Leiocephalus are usually terrestrial, but will occasionally forage in low vegetation or climb onto elevated perches to escape predators or avoid contact with intensely hot substrates. This female L. loxogrammus parnelli was photographed near the mouth of Pigeon Creek. Photograph by Tiffany Schultheis.

\section{Results}

We made 823 observations of 66 adult males, 398 small adults, and 358 juveniles (Table 1). Activity (Fig. 5) was bimodal, with peaks of comparable magnitude during midmorning and late afternoon. When broken down by age group (Fig. 6), adults exhibited bimodal peaks in activity similar to those for all lizards observed, but the pattern in juveniles approached a unimodal pattern with the peak in activity during late afternoon. Significantly more lizards were associated with vegetation $(583)$ than rocks $\left(240 ; \chi^{2}=74.7\right)$, in shade (546) than in sun $\left(276 ; \chi^{2}=45.9\right)$, and on the ground (815) than on elevated perches $\left(8 ; \chi^{2}=521.0\right)$ (for all comparisons, $\mathrm{df}=1, \mathrm{P}<0.0001)$. Mean hourly temperature during the sampling periods was $31.9 \pm 2.9^{\circ} \mathrm{C}\left(27.6-35.1^{\circ} \mathrm{C}\right.$, highest at $1230 \mathrm{~h}$, lowest at $0730 \mathrm{~h}$ ). Mean ambient temperature was significantly higher when individuals were in the sun $(33.1$ $\left.\pm 2.8^{\circ} \mathrm{C}, 25.0-36.9^{\circ} \mathrm{C}\right)$ than in the shade $\left(32.4 \pm 3.0^{\circ} \mathrm{C}\right.$, $\left.25.0-36.9^{\circ} \mathrm{C} ; \mathrm{t}=2.98, \mathrm{df}=820, \mathrm{P}=0.003\right)$. Temperatures when lizards of different size classes were encountered did not differ significantly (adult males: $32.7 \pm 2.7^{\circ} \mathrm{C}, 27.4-36.9^{\circ} \mathrm{C}$; 


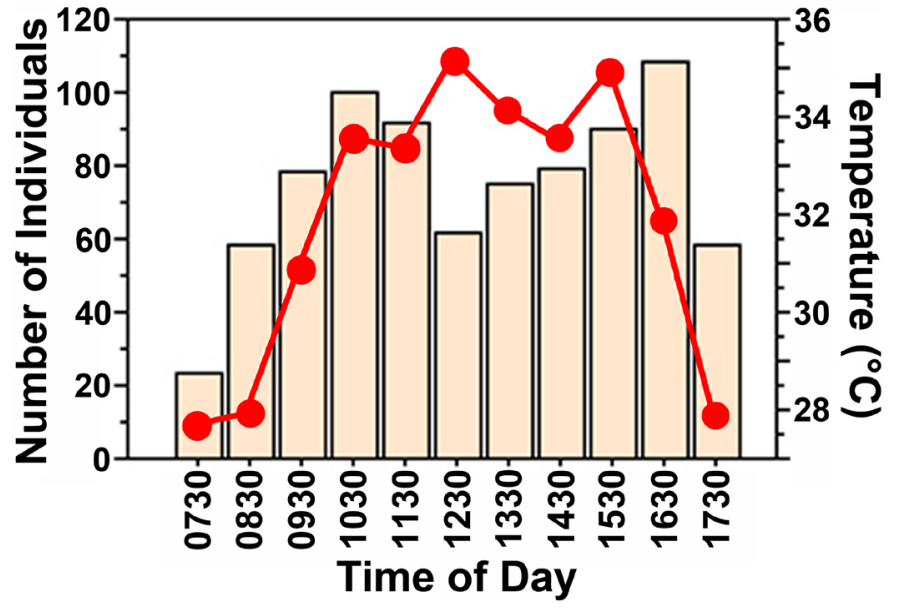

Fig. 5. Number of individual San Salvador Curly-tailed Lizards (Leiocephalus loxogrammus parnelli) active throughout the day and mean temperatures for the three-day sampling period.

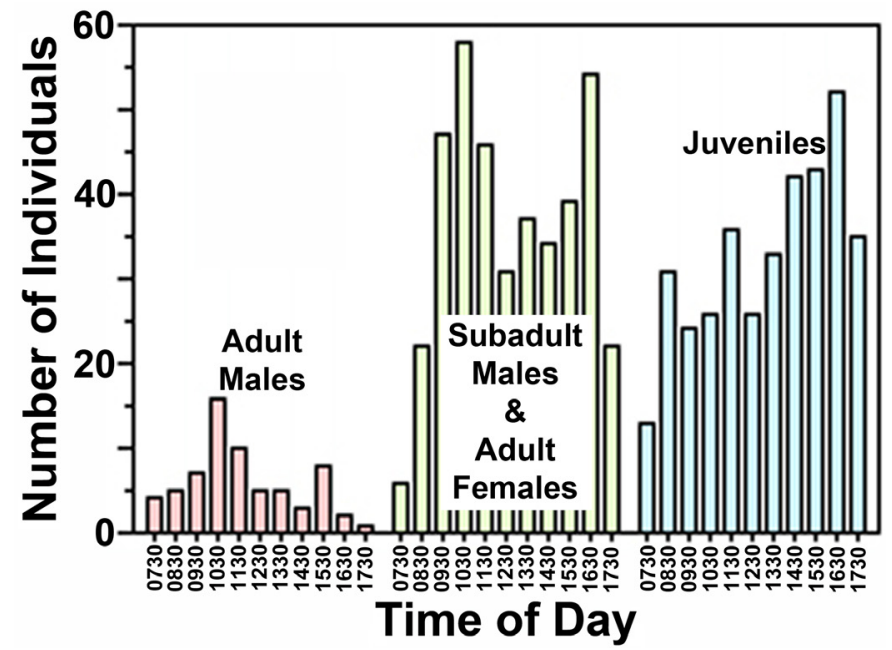

Fig. 6. Number of individual San Salvador Curly-tailed Lizards (Leiocephalus loxogrammus parnelli) of various age/size groups active throughout the day.

Table 1. Numbers of San Salvador Curly-tailed Lizards (Leiocephalus loxogrammus parnelli) encountered during hourly surveys near "Watling's Castle" on San Salvador in May 2013. Numbers of adult males, small adults, and juveniles are followed in parentheses by the percentage of all individuals encountered during that time period.

\begin{tabular}{|c|c|c|c|c|c|c|c|c|}
\hline Time & $\mathrm{N}$ & $\begin{array}{c}\text { Temp. } \\
\left({ }^{\circ} \mathrm{C}\right)\end{array}$ & $\begin{array}{l}\text { Adult } \\
\text { Males }\end{array}$ & $\begin{array}{l}\text { Small } \\
\text { Adults }\end{array}$ & Juveniles & $\begin{array}{c}\text { Percent } \\
\text { on Rocks }\end{array}$ & $\begin{array}{l}\text { Percent } \\
\text { in Sun }\end{array}$ & $\begin{array}{c}\text { Percent on } \\
\text { Elevated } \\
\text { Perches }\end{array}$ \\
\hline 0830 & 58 & 27.9 & $5(8.6)$ & $22(37.9)$ & $31(53.4)$ & 32.8 & 27.6 & 0.0 \\
\hline 0930 & 78 & 30.8 & $7(9.0)$ & $47(60.3)$ & $24(30.8)$ & 39.7 & 38.5 & 1.3 \\
\hline 1130 & 92 & 33.3 & $10(10.9)$ & $46(50.0)$ & $36(39.1)$ & 29.3 & 38.0 & 2.2 \\
\hline 1230 & 62 & 35.1 & $5(8.1)$ & $31(50.0)$ & $26(41.9)$ & 33.9 & 46.8 & 1.6 \\
\hline 1330 & 75 & 34.1 & $5(6.7)$ & $37(49.3)$ & $33(44.0)$ & 25.3 & 36.0 & 0.0 \\
\hline 1730 & 58 & 27.9 & $1(1.7)$ & $22(37.9)$ & $35(60.3)$ & 34.5 & 43.1 & 1.7 \\
\hline
\end{tabular}

small adults: $32.5 \pm 2.8^{\circ} \mathrm{C}, 25.0-36.9^{\circ} \mathrm{C}$; juveniles: $32.7 \pm$ $3.1^{\circ} \mathrm{C}, 25.0-36.9^{\circ} \mathrm{C} ; \mathrm{F}=0.38$, df $=2, \mathrm{P}=0.68$ ).

The mean percentage of adult males active during each sampling period was $8.4 \pm 5.0 \%(1.7-17.4 \%$, with the highest percentage at $0730 \mathrm{~h}$ and the lowest at $1730 \mathrm{~h}$ ), small adults $46.0 \pm 9.7 \%(26.1-60.3 \%$, highest at $0930 \mathrm{~h}$, lowest at 0730 h), and juveniles $45.6 \pm 10.6 \%$ (26.0-60.3\%, highest at 1730 $\mathrm{h}$, lowest at $1030 \mathrm{~h})$. The mean percentage of individuals on rocks was $29.9 \pm 7.0 \%(15.2-39.7 \%$, highest at $0930 \mathrm{~h}$, lowest at $1430 \mathrm{~h})$, in sun $32.4 \pm 11.1 \%(8.7-46.8 \%$, highest at
$1230 \mathrm{~h}$, lowest at $0730 \mathrm{~h}$ ), and on elevated perches $1.2 \pm 1.3 \%$ (0-4.3\%, highest at $0730 \mathrm{~h}$, lowest at 0830 and $1330-1630 \mathrm{~h})$.

\section{Discussion}

That juveniles comprised such a large proportion of the population (43.5\%) was suggestive of high annual turnover in the population. That abundance of juveniles, presumably hatched late in 2012, and the absence of neonates implies that reproductive activity is seasonal and timed to coincide with the rainy season, a pattern consistent with that of species 
of Leiocephalus for which data exist (Henderson and Powell 2009 and references therein). Mid-May is the very beginning of the rainy season in the Bahamas, a period during which food for neonates is presumably not sufficiently abundant.

Activity patterns are likely to vary by season and undoubtedly are affected by local weather conditions. Although some individuals might be active at any time of day, many species of Leiocephalus exhibit bimodal activity patterns such as that observed in this study. Such patterns have been described in L. psammodromus, L. personatus, L. raviceps, and L. macropus (Henderson and Powell 2009 and references therein) and a similar pattern is evident in a population of $L$. carinatus on Eleuthera (Fig. 7). Bimodal activity peaks are timed to avoid the hottest times of day (e.g., Huey and Pianka 1977), when lizards seek refuge under cover (e.g., Cooper 2007; Henderson and Powell 2009), and, in fact, the lowest midday activity coincided with the highest daily temperature at $1230 \mathrm{~h}$ (Fig. 5).

Adult males were proportionately more frequently encountered in the morning, presumably reestablishing ownership of their territories. Ord (2008) described early and late peaks in territorial behavior in Jamaican anoles, although a similar peak late in the day was not evident in our data. Although ambient temperatures when lizards in different size classes were encountered did not differ significantly, juveniles were proportionately more abundant early and late in the day, possibly taking advantage of their smaller sizes and corresponding higher surface-to-volume ratios to exploit cooler periods when larger individuals might find it more difficult to elevate body temperatures to peak efficiencies (e.g., Muth 1977). The proportional representation of small adults showed no such patterns, suggesting that they might be more adept at regulating body temperature by shuttling between sun and shade (e.g., Cowles and Bogert 1944), changes in posture (e.g., Muth 1977), or shifting microhabitats (e.g., Angilletta et al. 2009).

Our microhabitat data were somewhat unexpected. We had anticipated that individuals active early and late in the day would be disproportionately associated with hotter substrates (rocks) and more likely to be perched in sunny locations. Although somewhat surprising, periods when lizards were observed in the sun were warmer than when individuals were in shade, the opposite of what would be expected, our data revealed no obvious bias for sun or rocks during cooler periods. However, the percentages of lizards on rocks and in sun were generally lower during the hot early afternoon hours.

We observed very few individuals on elevated perches, reinforcing the generalization that Leiocephalus lizards are primarily terrestrial. Exploiting such perches has been associated with foraging (Burns et al. 1992) or efforts to escape contact with a very hot substrate (R. Powell, pers. comm.). Based on our very few observations of primarily juveniles on elevated perches, neither appears to apply in this instance. Other fac-

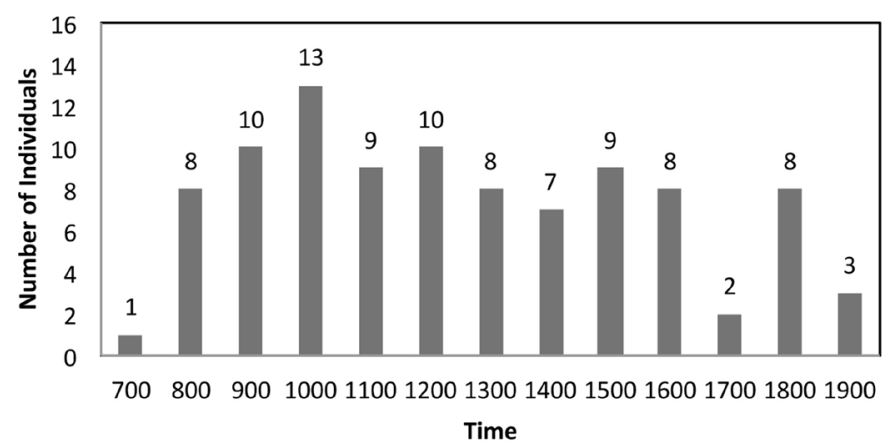

Fig. 7. Daily activity of the Northern Curly-tailed Lizard (Leiocephalus carinatus) over a three-day period in June 2012 on Eleuthera, Commonwealth of the Bahamas. Unpublished data courtesy of John S. Parmerlee, Jr. and Robert Powell.

tors, such as avoiding larger conspecifics or even predators might be applicable.

\section{Acknowledgements}

This project was in partial fulfillment of requirements for an Avila University class (IS 337 Tropical Culture and Nature: A History of Invasions; David Wissmann and Robert Powell, professors). Ben Dlugolecki, Ethan Karle, Kara Koehler, and Dianne Winter helped collect data. Robert Powell and Tyrun Flaherty provided guidance and helped in the field. John S. Parmerlee, Jr. and Robert Powell provided the activity graph for the Northern Curly-tailed Lizard (Leiocephalus carinatus, Fig. 7) based on previously unpublished data.

\section{Literature Cited}

Angilletta, M.J., Jr., M.W. Sears, and R.M. Pringle. 2009. Spatial dynamics of nesting behavior: Lizards shift microhabitats to construct nests with beneficial thermal properties. Ecology 90:2933-2939.

Burns, J.K., C.A. Cunningham, R.A. Dupuis, M.N. Trask, J.S. Tulloch, R. Powell, J.S. Parmerlee, Jr., K.L. Kopecky, and M.L. Jolley. 1992. Lizards of the Cayos Siete Hermanos, Dominican Republic, Hispaniola. Bulletin of the Chicago Herpetological Society 27:225-232.

Cooper, W.E., Jr. 2007. Escape and its relationship to pursuit-deterrent signaling in the Cuban Curly-tailed Lizard Leiocephalus carinatus. Herpetologica 63:144-150.

Cowles, R.B., and C.M. Bogert. 1944. A preliminary study of the thermal requirements of desert reptiles. Bulletin of the American Museum of Natural History 83:265-296.

Henderson, R.W., and R. Powell. 2009. Natural History of West Indian Reptiles and Amphibians. University Press of Florida, Gainesville.

Hillbrand, P.A., A.T. Sloan, and W.K. Hayes. 2011. The terrestrial reptiles of San Salvador Island, Bahamas. Reptiles \& Amphibians 18:154-166.

Huey, R.B. and E.R. Pianka. 1977. Seasonal variation in thermoregulatory behavior and body temperature of diurnal Kalahari lizards. Ecology 58:1066-1075.

Muth, A. 1977. Thermoregulatory postures and orientation to the sun: A mechanistic evaluation for the Zebra-tailed Lizard, Callisaurus draconoides. Copeia 1977:710-720.

Ord, T.J. 2008. Dawn and dusk "chorus" in visually communicating Jamaican anole lizards. The American Naturalist 172:585-592.

Schoener, T.W., J.B. Slade, and C.H. Stinson. 1982. Diet and sexual dimorphism in the very catholic lizard genus, Leiocephalus of the Bahamas. Oecologia 53:160-169.

Schwartz A. and R.W. Henderson. 1991. Amphibians and Reptiles of the West Indies: Descriptions, Distributions, and Natural History. University of Florida Press, Gainesville. 